\title{
Research on Literary Translation Capability and the Construction of
}

\section{Training Mode}

\author{
Hongte Chen \\ College of Fundamental Education, Sichuan Normal University, Chengdu 610066, China \\ mguo@163.com
}

\section{Key words: Literary Translation Capability, Training Mode, Construction}

\begin{abstract}
Literary translation is a complex code-switching and aesthetic reproduction process. It is not just the conversion at the level of language and more importantly, it is the experience and reproduction of the beauty and the communication of culture information. Therefore, the ability of literary translation should not only be trained from the vocabulary, syntax, semantics and pragmatics and other comprehensive aspects, but also needs to cultivate the translator's aesthetic capacity, English-thinking mode conversion capabilities, capabilities of the overall article comprehension and other comprehensive quality. In this article, we analyze the current training situation of literary translation talented person and based on which we proposed some requirements about training model of literary translation and analysis the literary translation training model and the construction about it.
\end{abstract}

\section{Introduction}

Translations are usually divided into non-literary translation and literary translation. Unlike non-literary translation for the translator of literary translation, the difficulty is not only to convey the ideas subject and style of the original author's style, but also embodies the translation concept and translation style of the translator. "To be able to not only deeply understand the original translator, grasp the essence of the original, but also be able to convey seamless original content and form of art mood"; while "ideology, the impact on the translation of literary ideas of the times is through translator to be embodied [1]. "Literary Translation is not a simple code-switching at the level of language, but the aesthetic and cultural experiences and reproduce and conveying information at a higher level. In literary translation practice, due to the inherent differences between the cultural backgrounds, cognitive thinking patterns and language, it is hard to match absolute peer in translation. Generally speaking, the symbols and carrier of cultural is language and an important form of culture is literature.

Research on translation ability has a direct guiding role in translation curriculum, teaching methods, teaching assessment and it is important to train the translation talents and assessment for the translation talents training. Researchers have different understandings of the concept of Literary Translation from different perspectives. Nord believes that the translator has the ability to translate different types of knowledge and the ability to be able to use knowledge to solve these problems [2]. Wilss proposed the concept of "super powers inter lingual" and he believed that inter-language translation capability is a comprehensive reflection of the ability to understand speech and recycling capabilities. The researchers defined the concept of translation capabilities differently, resulting in their ability to translate the established constitution system or pattern is also different. In fact, there is no one accepted through empirical effective translation capability mode [3]. 


\section{Related theories about translation}

Bell divided ability to translate into five kinds of knowledge, namely the target language knowledge, text type knowledge, knowledge of the source language, real-world knowledge and contrast knowledge. Neubert set the five parameters translation capabilities as the dimension of the ability: language, text capability, theme ability, cultural competence and conversion capabilities. The five abilities work together to form the learner's capability of translation. Beeby analyzed from the perspective of learning objectives translation capabilities that include the ability to translate the language conversion capability, the ability to compare the language, discourse contrast ability and nonverbal ability (such as the ability to use literature resources) four aspects. Alves stressed translation capabilities should be based on the ability of language and language use, the sum of this ability is a complex cognitive network, the knowledge, skills and strategies composition [4]. Ability to translate research group of the Autonomous University of Barcelona, Spain's ability to build a translation model, and is defined as the ability to translate the translator must possess the knowledge and skills system translation capabilities proposed model is divided into six dimensions: interpersonal skills, non-verbal ability, psychological and physiological factors, ability of professional operation, the ability to convert and strategic capabilities.

Ju Miao divided the ability to translate into three areas, constituting translation capabilities were systematic association of description and definition. She believes that the ability to translate the first performance on cognitive thinking skills translator, and concepts such as intuition, logical reasoning, and information processing capacity; followed on language skills, including the ability to select the language and expression, language conversion and coordination, rhetorical style and cultural awareness; finally it is the interpersonal skills, including the representation of knowledge, skills, and acceptance, creativity and resilience [5].

\section{The analysis of situation of translation talents training}

Translators are very important for translation career life. And the training of translators determines the rise and fall of our future translation career; while literary translators is the reserve army to promote literary translation career, the training of literary translators of the determine the future of literary translation career of energy No adjourned to past glories. With the formation of the global village, the team needs to literary translators expanding their own quality of translators are increasingly high requirements. Our universities are training high-level positions translators, translation concerns the reform of postgraduate education and teaching mechanism has become one of the important tasks of our moment. As a new era university educators, we naturally faced with constantly innovative graduate education philosophy, timely innovation postgraduate training mode, seriously think about how to effectively develop appropriate translation talents is the urgent issues should be on the needs of the new era.

Translation Studies in training personnel, and literary translation in the last century for a long period of time to get over a lot of attention, literary translator training translators was an important teaching, but since the new century began due to non-teaching literary translation or practical translation of restructuring, more attention to culture and trade or technical translation talents, therefore they deviate from this position of literary translation, language and literature rarely dedicated literary translation research. Master's degree in translation appeared in recent years (MTI) personnel training are mainly limited to non-literary translation, focusing on skills development and application of translation practice. Different training objectives and specifications MTI talent lies in the translation: translation of academic talent cultivation mainly for the cultural, educational and 
other needs of various enterprises and institutions, emphasizing the theoretical research, and professional degree-based translation talents, places cultivation fields of economy, trade, foreign affairs, foreign affairs, science and technology talent needed to translate the goal, "emphasis on practice and application, focusing on the training of high-level, application-oriented professionals with strong practical ability to translate, with distinctive expertise sex and occupational orientation. " [6]

Thus, the training mode of translators is facing new challenges in our country and the trend of reform is inevitable. Since the new era, due to the talent market demand shift, the provisions of the Ministry of Education in 2010, the scale of Applied Talents should catch up with academic talent, both adjusted enrollment ratio in 2015 should reach 1:1 structure, universities enrollment translators and even training specifications attendant change. While in graduate education in the process of this transition will inevitably be translated personnel training and practical light weight and even ignored the traditional academic situation. In fact, the understanding of this percentage 1: l should refer to two personnel training both. Emphasis on application-oriented translation talents, does not mean that academic translators are no longer relegated to secondary needs, instead, need to develop a better quality of academic quality translators. Academic Graduate education is facing in the future how to train translators applied to the new requirements facing new challenges on how to reform and innovation of its training model, not just cater to the status quo [7].

In recent years for the above requirements and challenges, a number of journals and newspapers published many articles on how to cultivate literary translators, such as "literary translators lean ", shortage of high-quality translation talent "; "The redefinition of 'translation of the master " etc. From the title, we can find the desire to reform and innovation on doubly interesting, which is obviously of concern literary translation Talents urgent call. Set up in the language and literature of literary translation direction should be a priority, develop a number of literary translators, you cannot "quantity" for the sake of "quality" in order to ensure that literary translation team will not interrupted.

Review the long-term postgraduate training of translation major, we can see that in the direction determine, curriculum and academic exploration, literature and translation, often disjointed phenomena between literary studies and translation studies, literary translation and non-literary translation, translation theory and practice of translation. For example, the direction of graduate literary classics to read Russian literature, although the aid interpretation of literary translation, but because of the training program curriculum, teaching content, teaching several objective factors such as time, personnel training, and educational philosophy and practice training model limitations and other issues, leading to teachers and students of different versions of the translation of good and bad, and translation differences due to different translators style caused little say, few people involved in the main study of literary translation or literary translators such subject. This means that literary students do not care about translation, and translation graduate also ignore literature and even doesn't know the literature. For outstanding graduate translators who translate the essence of it is poorly understood. As a result, personnel training graduate students to form a literary and translation, literary studies and literary translation studies, literary and non-literary translation unrelated situation, not to mention further guide graduate next debate literary translation and translation of literature, translated literature and foreign literature, ethnic literature, comparative literature, much less attention to the effective exchange translation teaching foreign literature and culture, to strengthen Chinese literary culture and other aspects of external communication [8].

This Literature Translation Training Mode is even in disjointed way and whether it is very unfavorable for our country both in the development and prosperity of literary career and translation 
career. The current status quo of China's translation talents training, we believe it is necessary to translate science graduate education direction of the current reforms, focusing on innovative thinking about how literary translation training model, and applied to a timely and effective personnel training in teaching practice.

\section{The relevant requirements of literary translation training mode}

In literary translation teaching process, teachers cannot be limited to do peer training in words and syntactic semantic translation of students, but also pay more attention to literature on the chapter level of the other exercises in order to translate the original text level, aesthetic level and cultural level of perfection implication, therefore, the need to strengthen the teaching practice in the translation from the comprehensive practice vocabulary, syntax, semantics and pragmatics, etc., in order to improve students' understanding of the chapter, the overall quality of Rhetoric and literacy and so on. American linguist and translator Nida's theory of "functional equivalence" has a positive reference on translation teaching in our country [9].

Nida propose two different forms of peer in the book "translating scientific Preliminary" (1964), such as: formal equivalence and dynamic equivalence, after which he again change "dynamic equivalence" to "functional equivalence". Nida pointed out that the pursuit of semantic translation to genre, and strive to target language using the closest and most natural of other languages, in order to reproduce the natural and proximate equivalent of two languages of information between primitives. First, we must take into account is the translation of information content and information into account body language, therefore, "is the most appropriate translation, natural, and peer language. Primitives from the semantic information to reproduce the stylistic language "; Secondly, vocabulary and syntax as well as at the level of discourse of which chapters peer refers semantics and pragmatics and for peer Nida further express:." Meaning is the most important, followed by the form. "

Since the form exists only on the level of vocabulary and syntax of language, it is not involving semantic and pragmatic level. Therefore, it limited to only form if the translation, it is very likely obscured the original language and cultural significance, thus impeding between different cultures exchange. According to Nida's theory, in literary translation teaching process, teachers should train students on the rhetorical level, pragmatic and stylistic adjustments on translation as the focus of the artistic process and the ability, and fully take into account the cultural characteristics between the original language and the target language to achieve the closest translation. However, due to the translation of basic vocabulary and syntax are, therefore, based on Chinese students' English-language skills, literary translation teaching students in the first text to strengthen the level of code-switching to other exercises to develop their language ability, and then a gradual transition to students' aesthetic and cultural dimensions.

First, cultivate students' aesthetic language ability in the lexical syntactic translation. According to the point of view of functional linguistics, the form is the expression of meaning and form plays an important role in terms of meaning embodied, is an integral part of the meaning. Thus, one of the aesthetic principles of literary translation is "shaped the United States", that means of expression language (language, text, etc.) and formalism performance methods. According to computer statistics, English expression, although very different, but there are still $45 \%$ of the English expression has on other forms of expression. Therefore, in the process of translation of literary works, and do not like some of the translator said, must paraphrase, sometimes the translation can be kept entirely in terms, sentence structure, and performance practices are consistent with the original means of metaphor. Although different nations have different cultural backgrounds, but 
after all, between the same or similar, is reflected in the language and culture, the phenomenon appears certain fit. In the translation of literary works when dealing with similar expressions, it is easier for the translator to handle vocabulary and syntax of other issues. As in foreign literature, often use a lot of proverbs and idioms, which contains a form with the connotation that full reciprocity situations.

Second, enlighten the attitude for cultural tolerance of students from semantic peer and thinking mode conversion. In most cases, the translation is completely natural and so on and so on and due to the difference between the structure of language and culture, in fact, difficult to achieve, and therefore, according to Nida's theory of literature in translation, the translator should be based on the principle of dynamic equivalence translations as accurate reproduction of the original language and cultural connotations in the target language, so in this case, in the classroom teaching practice students need to have a destination in the target language semantic and syntactic structure allows as far as possible within the scope of the exact translation of the original meaning, that meaning and rhetorical semantic association reproduce the original meaning.

Third, peer literacy and text comprehension has a significant educational meaning on students. Although translation is the conversion activities between primitive language and target language, but it is not a simple convert between code words. Its ultimate aim is to make the translation to convey accurate information to produce the desired effect and impact on the reader. Due to the differences between English and Chinese cultural background, the same literal meaning may have completely different implications, and the implications of the speaker or writer is trying to convey the true meaning. - American poet Robert Frost poem is considered as lost in translation thing, so when the translation of literary works, in order to avoid the original poetic loss, we must translate Pragmatic students peer awareness, which is in the process of translation based on comparison of the two languages, according to the context to determine the behavior of discourse act carried out an equivalent translation. It is in pursuit of different levels vocabulary, syntax and semantics, such as linguistics, informality in the original form, but only to save the original content, with the translation of the closest, most natural expression of the content of other statements out of order, etc. effect. Translation difficulty does not lie in the surface meaning of the text, but in between the lines of the implication that illocutionary act discourse. Chinese and English are sometimes not equivalent in form or surface meaning, but the pragmatic point of view, you can take some appropriate translation methods to solve problems in literary and cultural differences [10].

\section{The attempt of literary translator training mode reform}

Based on the one-way status of literary translation talent training mode and its new challenges, we believe that it is necessary to take some measures to improve the situation constantly, innovative educational philosophy and make some appropriate adjustments for the direction of translation talent training. For example, you can have the direction of translation studies, based on strengthening the research of literary translation, additional courses and related literary translation, started studying theoretical and practical issues related to literary translation; may also personnel training in the direction of literature in translation studies and translation, literary translation and non-literary translation, literary studies and translation studies combine theoretical research and the translation of literary translation practices; addition, you can learn to translate academic degree in personnel training and professional personnel training model combines practical translation. In the course of the study focuses on some of the best literary translators and translation studies classic country, in order to enhance the overall quality of cognitive ability and research postgraduate literary translation direction. After several years training to fight a large number of literary 
translators, they will both be competent literary translation, literary translation research output can even excellent series of literary translators results provide a theoretical reference for the future development of literary translation, as descendants of the older generation to pass the baton translator, while the research literature also has some inspiration. This is for the prosperity of our country's literature and translation business is bound to play a complementary role and win.

In short, the creation of literary translation research has broadened the scope of translation studies, and carry out the main study of literary translators not only opens up another door for the translation of literary career, but also for the study of literature contribute to the cause. Literature and translation was originally one, they cannot be completely separated. Literature is inseparable translation, literary translation is also built on top of literary studies; Meanwhile, literary translation studies is also inseparable from literary studies and literary criticism, literary studies and criticism without literary translation studies do support apparently is not perfect. Murray talked about various aspects of the subject translator, multi-level, multi-angle studies have pointed imagine the following three aspects: "First, we must expand the research object plane, the second is to be carried out with the famous multi-translation-related aspects of research, third is to strengthen the relevant masters of translation studies academic exchange activities ". Murray's this idea, the moment for us to think about how to solve the puzzles that exist in postgraduate education, training new translation talent, no doubt with some inspiration.

\section{The analysis of literary translation ability training pattern}

1. Cultivate the drive force. First, making a guidance and education for the student's values to establish a correct translation behavioral values and to "interpret something" and train students' translation attitude and appreciation; secondly, to strengthen students' psychological quality, experiential learning, interactive teaching and other ways to develop their self-confidence; Finally, students' background knowledge is also indispensable link. We should set up a special international cultural program to enhance students' background knowledge translation.

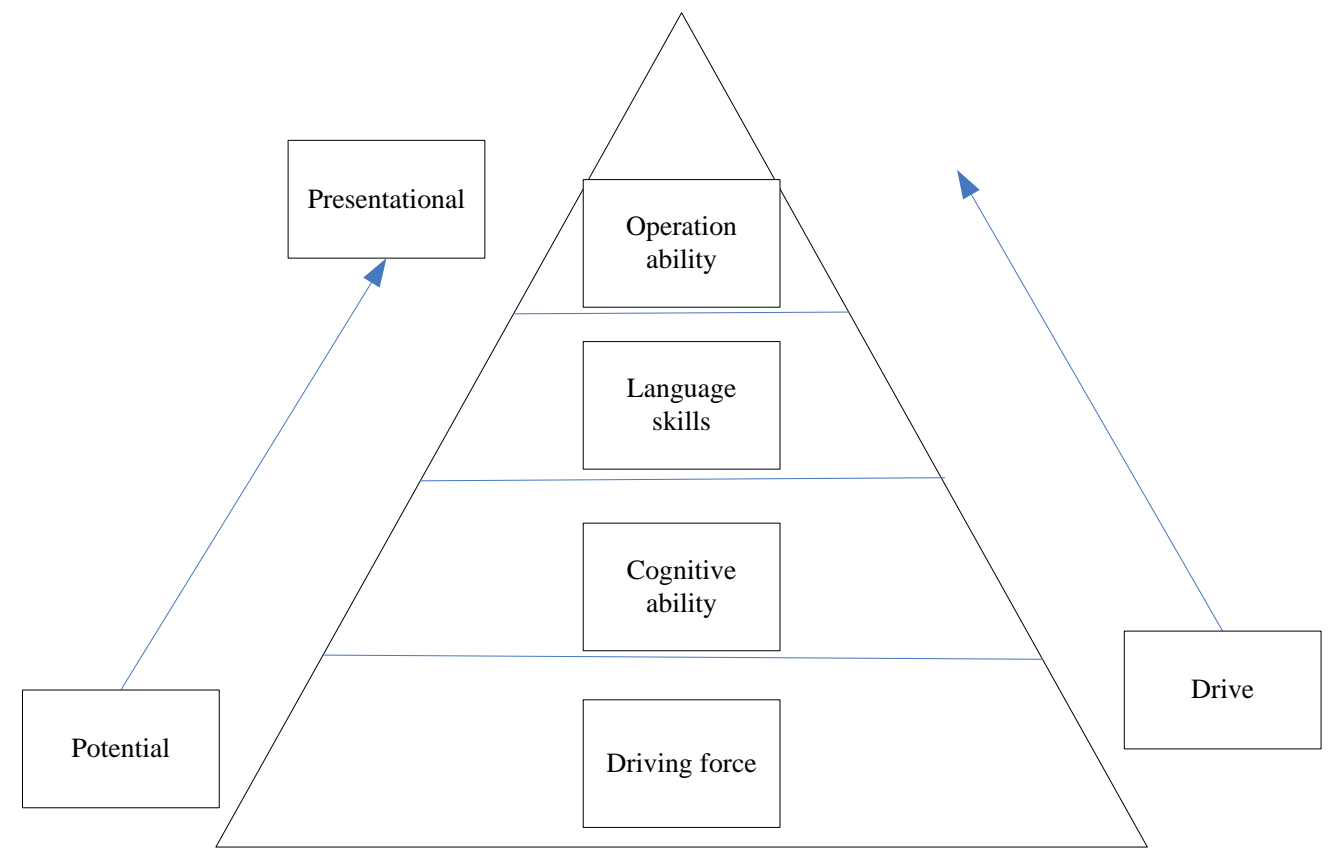

Fig. 1: The pyramid model of elements of ability to translate 
2. Develop language skills. Language ability is the ability of translator to master and use the language knowledge. It helps to improve language skills and cognitive abilities improve operational capabilities, knowledge and language from the language should be used in terms of both training in teaching practice. Teaching students to develop continuously strengthened in terms of grammar, vocabulary and rhetoric, and be pragmatic point of view and the translation from the original angle, expression, synthesis and other aspects of training, and gradually improve their bilingual skills.

3. Cognitive development. Cognitive ability is the ability of translator to know translation features, such as knowledge of the law and ability to grasp. The translator can help improve their cognitive ability to control the behavior of translation. In the logic capacity, although the foreign language classroom has about logic, memory and attention and other aspects of training, but only interspersed in teaching classroom session, fragmentation, special programs should be set up in this regard. In addition, the complexity of translation requires students to have a certain degree of understanding and the ability to create

4. Develop operational capabilities. First, we need to guide students to translate every process activity as a system, make an effective planning before, during and after the translation, and develop their competence in the use of resources, information processing, and constantly changing translation context and information conditions of translator in training to strengthen their resilience.

\section{Conclusion}

Literary translation is a complex process that requires repeatedly read from the vocabulary, syntax, semantics and pragmatics aspects of the original article and making an art processing from the text level, aesthetic and cultural dimensions by using a variety of methods. And because of this, literary translation has a higher requirement for students on their comprehensive ability. In literary translation training, according to Nida's translation theory, it is with strong operational meaning to make a comprehensive training for students from the vocabulary, syntax, semantics and pragmatics, etc. In the specific teaching practice, students in the early stages can practice different small content, and then combined with the students' practical mastery of the various sub-practice to carry out a suitable comprehensive exercise to both improve students' literary translation ability and their overall quality.

\section{References}

[1] Zhihong Yang, Kefei Wang. Foreign Language Teaching, v.1, n.4, p.91-95, November 2010.

[2] Weidong Dai. Journal of Foreign Languages, v.53, n.10, p.3-6, June 2000.

[3] Yueqing Du. Foreign Language Teaching, v.11, n.2, p.33-36, February 2007.

[4] Wenzhong Hu. Foreign Language Teaching and Research, v.189, n.4, p.163-169, April 2009.

[5] Jinqing Yao. East Journal of Translation, v.27, n.1, p.8-11, April 2010.

[6] Xunying Zhou. Journal of Foreign Languages, v.12, n.1, p.36-42, June 2010.

[7] Zhixiang Zhuang, ShuYueqing. Journal of Foreign Languages, v.12, n.1, p.14-23, March 2007.

[8] Liping Mei. The China Daily, v.5, n.3, p.149-158, March 2010.

[9] Depei Tian. Comparative Literature in China, v.2, n.3, p.90-97, February 2001.

[10]Wenming Zhong, Journal of Changsha Railway University, v.2, n.3, p.148-150, February, 2011. 